\title{
KEANEKARAGAMAN DAN KELIMPAHAN DIATOM (Bacillariophyceae) DI PANTAI JERANJANG DESA TAMAN AYU KECAMATAN GERUNG KABUPATEN LOMBOK BARAT
}

\author{
Hasanah Nurlaelatun ${ }^{1}$, LaluJapa ${ }^{2}$, Didik Santoso ${ }^{2}$ \\ ${ }^{1}$ Mahasiswa Pendidikan Biologi FKIP Universitas Mataram \\ ${ }^{2}$ Dosen Pendidikan Biologi FKIP Universitas Mataram \\ Email: nurlaelatun96@yahoo.com
}

Diterima: 28 Januari 2018. Disetujui: 28 Maret 2018. Dipublikasikan: 14 Mei 2018

\begin{abstract}
ABSTRAK
Pantai Jeranjang yang terletak di desa Taman Ayu merupakan salah satu daerah buangan limbah cair karena terdapat PLTU (Pembangkit Listrik Tenaga Uap) yang menggunakan air laut sebagai pendingin dan akhirnya dibuang kembali ke laut. Tujuan penelitian ini yakni untuk mengetahui keanekaragaman dan kelimpahan diatom (Bacillariophyceae) di Pantai Jeranjang Desa Taman Ayu Kecamatan Gerung Kabupaten Lombok Barat. Metode penentuan titik sampling dan waktu sampling menggunakan purposive sampling method. Data diatom dianalisis untuk parameter indeks keanekaragaman, indeks kemelimpahan, indeks kemerataan dan nilai penting. Persen kesamaan antar stasiun ditentukan berdasarkan Bray Curtis Cluster Analysis menggunakan program biodiversity versi 2. Hasil penelitian menunjukkan spesies diatom yang teridentifikasi di Pantai Jeranjang terdiri dari 1 kelas, 2 ordo, 17 genus dan 26 spesies. Kemelimpahan spesies diatom di perairan Pantai Jeranjang sebesar 786,944individu/liter. Indeks keanekaragaman spesies diatom tergolong sedang yakni 1,383 dan kemerataan spesies diatom yakni 0,424 (penyebaran kurang merata). Hasil Bray-Curtis cluster analysis menunjukkan bahwa berdasarkan parameter biologi dan gabungan antara parameter bilogi dan parameter lingkungan, persen kesamaan tertinggi terdapat antara titik sampel I dan titik sampel II berturut-turut sebesar $78,781 \%$ dan $80,63 \%$. Sedangkan berdasarkan parameter lingkungan persen kesamaan tertinggi terdapat antara titik sampel I dan titik sampel III sebesar 99,030\%.
\end{abstract}

Kata Kunci :Pantai Jeranjang, PLTU, Diatom

\begin{abstract}
Jeranjang coastal waters is a part of Taman Ayu village. The coastal waters of Jeranjang has been an area of liquid waste disposal of the Electric Steam Power Plant Jerajang. The purpose of this research were to know diversity and abundance of diatom (Bacillariophyceae) inthe coastal waters of Jerajang Taman Ayu village Gerung districts west Lombok. Sites and times of sampling were determined by using purposive sampling method. Data of diatom were analyzed for density,diversity, andevenness indexs and percentage important value. Percentage similarity of among stations was determined based on the BrayCurtis cluster analysis using biodiversity program-version two. The results showed that diatom species of Jeranjang coastal waters consist of 1 class, 2 orders, 17 genus and 26 species. The abundance of diatom community in Jeranjang coastal waters was 786,944individu/liter. Diversity and evenness indexs of diatom species were 1,383 (intermediate status) and 0,424 (lack of dispersal). The highest percentage similarity was on biological parameters and the relationship between biological parameters and environmental parameters for between sample site I and sample site II $(78,781 \%$ and $80,63 \%)$. Based of environmental parameters the percentage similarity of between sample site I and III was of $99.030 \%$.
\end{abstract}

Key words :Jerajang Coastal Water,Electric Steam Power Plant, Diatom 


\section{PENDAHULUAN}

Diatom merupakan salah satu organisme yang biasa digunakan sebagai bioindikator lingkungan. Hal ini dikarenakan diatom sangat mempengaruhi kehidupan di perairan karena memegang peranan penting sebagai sumber makanan dalam rantai makanan bagi berbagai organisme laut dan berperan dalam perpindahan karbon, nitrogen dan pospat (Siregar et al., 2008).Melalui rantai makanan ini seluruh fungsiekosistem dapat berlangsung. Seluruh hewan laut seperti udang, ikan, cumi-cumisampai paus yang berukuran raksasa bergantung pada fitoplankton, baik secara langsung maupun tidak langsung (Nontji, 2008).

Menurut Soeprobowati (2011), diatom sebagai bioindikator sangat efektif dan ekonomis karena diatom mempunyai beberapa keunggulan dibandingkan dengan organisme lain, diantaranya diatom mempunyai distribusi yang luas dengan populasi yang bervariasi, mempunyai peran penting di dalam rantai makanan, siklus hidup pendek, cepat bereproduksi, dijumpai di hampir semua substrat sehingga mampu merekam sejarah habitatnya, serta banyak dari spesiesnya yang sensitif terhadap perubahan lingkungan sehingga cepat merespon, mampu merefleksikan perubahan-perubahan kualitas air dalam jangka pendek maupun jangka panjang, mudah dalam pengambilan sampel, analisis dan identifikasinya.

Pantai Jeranjang yang terletak di desa Taman Ayu merupakan salah satu daerah buangan limbah karena terdapat PLTU (Pembangkit Listrik Tenaga Uap) dimana bahan pembangkitnya berupa batubara. Pada PLTU diperlukan sistem pendingin utama yang berfungsi untuk menyediakan dan memasok air pendingin yang diperlukan untuk mengkondensasikan uap bekas dan drain uap di dalam kondensor dan menggunakan air pendingin yang dipasok secara kontinyu dari laut yang dipompakan ke kondensor untuk akhirnya dibuang kembali keasalnya. Menurut Susiati et al. (1999), limbah PLTU yang suhunya melebihi atau di bawah ambang batas maka akan pengaruh terhadap ekosistem laut dangkal seperti estuaria, mangrove, terumbu karang, padang lamun dan biota yang berasosiasi.

Pengembangan studi tentang Diatom (Bacillariophyceae)yang berada di sekitaran daerah pembuangan PLTU masih terbatas. Untuk itu, perlu adanya penelitian mengenai "Kelimpahan diatom (Bacillariophyceae) di Pantai Jeranjang Desa Taman Ayu Kecamatan Gerung Kabupaten Lombok Barat" sehingga dapat menjadi sumber acuan dan informasi dalam kegiatan pembelajaran maupun aktivitas praktikum yang terkait pada KD 3.6 untuk jenjang siswa kelas 1 SMA.

\section{BAHAN DAN METODE}

Pengambilan sampel air laut dilakukan di 3 (tiga) titik (Gambar 1). Faktor fisika-kimia (suhu air, suhu udara, dan salinitas) perairan diukur langsung di lapangan (in situ) pada saat pengambilan sampel air.

Sampel air laut sebanyak $50 \mathrm{ml}$ diambil 2 (dua) kali ulangan pada setiap titik pengambilan sampel menggunakan jaring plankton bermata jaring berukuran $20 \mu \mathrm{m}$. Setiap sampel diawetkan dalam larutan formalin 4\%. Pengamatan dan identifikasi jenis diatom di laksanakan di Laboratorium Biologi FMIPA Universitas 
Mataram. Identifikasi jenis dilakukan secara morfologi berdasarkan sumbersumber yang ditulis oleh Smith (1950), Davis (1955), Thomas (1997, Wehr dan Sheath (2003), Al-Kandari et al. (2009), Kim (2010), Park (2012), dan Bellinger dan Sigee (2015).

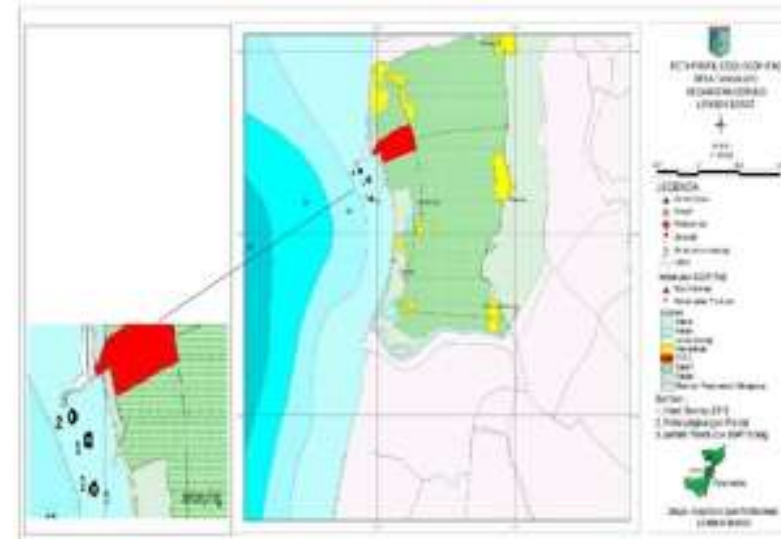

Gambar 1Posisi Lokasi Penelitan, Pantai Jeranjang Desa Taman Ayu Kecamatan Gerung Kabupaten Lombok Barat.

Faktor fisika-kimia (salinitas, suhu air, suhu udara) di ukur langsung di lokasi penelitian di setiap titiknya.

Analisis data parameter biologi meliputi kelimpahan, indeks keanekaragaman, indeks kemerataan dan nilai penting.Indeks Keanekaragaman Spesies digunakan untuk mengetahui keanekaragaman hayati biota yang diteliti (Romimohtarto dan Juwana, 2001). Indeks keanekaragaman jenis dihitung berdasarkan rumus Shannon \& Wiener (Odum, 1993).Perhitungan kelimpahan individu fitoplankton menggunakan rumus Romimohtarto dan Juwana, 2001.Indeks kemerataan menggunakan rumus dari PIELOU (Romimohtarto dan Juwana, 2001), sedangkan perhitungan nilai penting fitoplankton dapat menggunakan rumus modifikasi dari
Hardjosuwarno (1994) dalam Al Idrus (2014) dengan modifikasi.

\section{HASIL DAN PEMBAHASAN}

Pengukuran parameter fisika kimia perairan di Pantai Jeranjang meliputi salinitas, suhu air, dan suhu udara. Di perairan Pantai Jeranjang salinitas air relatif lebih bervariasi berfluktuasi pada rentang nilai dari 28 sampai $34 \%$. Berbeda dengan salinitas, suhu air dan suhu udara tidak jauh berbeda di ketiga titik sampel penelitian. Rentangan suhu air pada keempat waktu penelitian berkisar antara $24-29^{\circ} \mathrm{C}$, sedangkan suhu udaranya berkisar antara $25-29^{\circ} \mathrm{C}$. Data faktor fisika-kimia di pantai Jeranjang disajikan dalam Tabel 1 berikut ini.

Tabel 1Data Fisika dan Kimia Perairan Pantai Jeranjang

\begin{tabular}{|c|c|c|c|c|c|}
\hline \multirow{2}{*}{ No. } & \multirow{2}{*}{ Parameter } & \multirow{2}{*}{ Waktu } & \multicolumn{3}{|c|}{ Lokasi } \\
\hline & & & 1 & 2 & 3 \\
\hline \multirow{4}{*}{1.} & \multirow{4}{*}{$\begin{array}{l}\text { Salinitas } \\
(\%\end{array}$} & $07 / 02 / 2017$ & 32 & 32 & 34 \\
\hline & & $21 / 02 / 2017$ & 31 & 34 & 30 \\
\hline & & $07 / 03 / 2017$ & 28 & 29 & 28 \\
\hline & & $24 / 04 / 2017$ & 30 & 32 & 30 \\
\hline \multirow{4}{*}{2.} & \multirow{4}{*}{ Suhu air $\left({ }^{\circ} \mathrm{C}\right)$} & $07 / 02 / 2017$ & 24 & 24 & 26 \\
\hline & & $21 / 02 / 2017$ & 25 & 25 & 26 \\
\hline & & 07/03/2017 & 27 & 28 & 29 \\
\hline & & $24 / 04 / 2017$ & 27 & 26 & 27 \\
\hline \multirow{4}{*}{3.} & \multirow{4}{*}{$\begin{array}{l}\text { Suhu udara } \\
\left({ }^{\circ} \mathrm{C}\right)\end{array}$} & $07 / 02 / 2017$ & 26 & 25 & 25 \\
\hline & & $21 / 02 / 2017$ & 27 & 28 & 28 \\
\hline & & $07 / 03 / 2017$ & 28 & 29 & 29 \\
\hline & & $24 / 04 / 2017$ & 29 & 29 & 29 \\
\hline
\end{tabular}

Dalam penelitian ini teridentifikasi 26 spesies diatom yang terdiri dari 17 genus, 2 ordo dari ordo Centrales dan Pennales dan 1 kelas yaitu Bacillariophycea.Jumlah spesies diatom yang ditemukan di Pantai Jeranjang lebih 
tinggi dibanding 20 spesies diatom di laut Padang Galak (Purnomo et al., 2015). Tetapi lebih sedikit daripada 153 spesies di perairan pelabuhan Lembar (Japa, 2000), dan di Pantai Jawa Utara Tengah sebanyak 147 spesies diatom (Soeprobowati dan Suedy, 2010).Titik sampel I memiliki jumlah spesies terbanyak yakni 21 spesies, Titik sampel II memiliki jumlah spesies terendah yakni 15 spesies, sedangkan titik sampel III dengan 18 spesies. Perbandingan proporsi jumlah taksa dan jumlah individu diatom pada masing-masing titik sampling dapat dilihat pada Tabel 2.

Tabel 2.Data Proporsi Jumlah Taksa dan Individu Diatom pada Masingmasing Titik Sampling Penelitian

\begin{tabular}{|c|c|c|c|c|}
\hline No. & Spesies & $\begin{array}{c}\text { Titik } \\
\text { sampel } \\
\text { I }\end{array}$ & $\begin{array}{c}\text { Titik } \\
\text { Sampel } \\
\text { II }\end{array}$ & $\begin{array}{c}\text { Titik } \\
\text { Sampel } \\
\text { III }\end{array}$ \\
\hline 1. & $\begin{array}{l}\text { Asterionellopsis } \\
\text { gracialis }\end{array}$ & 318 & 160 & 131 \\
\hline 2. & $\begin{array}{l}\text { Basteriastrum } \\
\text { hyalinum }\end{array}$ & 24 & 63 & 6 \\
\hline 3. & Biddulphia mobiiensis & 4 & - & 2 \\
\hline 4. & B. obtusa & - & - & 1 \\
\hline 5. & Chaetoceros affine & 60 & 23 & 4 \\
\hline 6. & C. brave & 7 & 14 & 3 \\
\hline 7. & C. didymus & 15 & - & - \\
\hline 8. & C. laeve & 10 & 1 & 4 \\
\hline 9. & C. subsecendum & 25 & 63 & 33 \\
\hline 10. & Coscinodiscus lacustris & 9 & 12 & 7 \\
\hline 11. & C. radiatus & 1 & - & - \\
\hline 12. & Cymbella obtusiucula & - & 1 & - \\
\hline 13. & Diatoma hyalina & 18 & - & - \\
\hline 14. & Ditylum sol & 3 & 1 & - \\
\hline 15. & Gyrosiga acuminatum & 3 & - & 2 \\
\hline 16. & Melosira numuloides & - & - & 2 \\
\hline 17. & M. sulculata & 4 & - & - \\
\hline 18. & Nitzschia longissima & 3 & 1 & 2 \\
\hline 19. & N. sigma & 5 & 1 & 3 \\
\hline 20. & $\begin{array}{l}\text { Pleurosigma } \\
\text { intermedium }\end{array}$ & 1 & - & - \\
\hline 21. & Skeletonema costatum & 798 & 581 & 319 \\
\hline 22. & Surirella gemma & - & - & 3 \\
\hline 23. & Synedra formosa & 1 & - & 3 \\
\hline 24. & S. ulna & 3 & 1 & - \\
\hline 25. & Thalassiosira pacifica & - & 1 & 2 \\
\hline 26. & $\begin{array}{l}\text { Thalassiotrix } \\
\text { fraunfeldii }\end{array}$ & 43 & 5 & 23 \\
\hline
\end{tabular}

Indeks keanekaragaman spesies diatom antar titik sampling di Pantai Jeranjang berkisar antara 1,251,37.Indeks keanekaragaman spesies diatom di Pantai Jeranjang tergolong sedang yaitu 1,38. Nilai indeks keanekaragaman spesies diPantai Jeranjang lebih tinggi dibandingkan indeks keanekaragaman di perairan Intertidal Kota Kupang, yang dilaporkan oleh Haninunaet al. (2015) yakni 0,0050,102 dan dikategorikan rendah. Pengklasifikasian tersebut berdasarkanFitriana (2006), apabila $H^{\prime}<1,0 \quad$ keanekaragaman spesies dikategorikan rendah. Jika nilai $1,0<\mathrm{H}^{\prime}<3,322 \quad$ dikategorikan keanekaragaman sedang. Apabila H'>3,322 dikategorikan keanekaragaman tinggi. Indeks kemerataan spesies di Pantai Jeranjang yaitu 0,42 yang berarti penyebarannya kurang merata.Choirun et al. (2015) menyatakan, bahwa apabila kemerataan mendekati nol berarti kemerataan antar spesies tergolong rendah dan sebaliknya kemerataanspesies yang mendekati satu dapat dikatakan kemerataan spesies tergolong merata atau sama. Rendahnya indeks kemerataan spesies di Pantai Jeranjangmenandakan ada beberapa spesies yang mendominasi pada salah satu lokasi saja dalam jumlah individu yang besar. Namun, tidak ditemukan dalam titik sampling lainnya sehingga berdampak pada rendahnya kemerataan jenis spesies yang ada. Indeks keanekaragaman dan indeks kemerataan di perairan Pantai Jeranjang disajikan pada Gambar 2. 


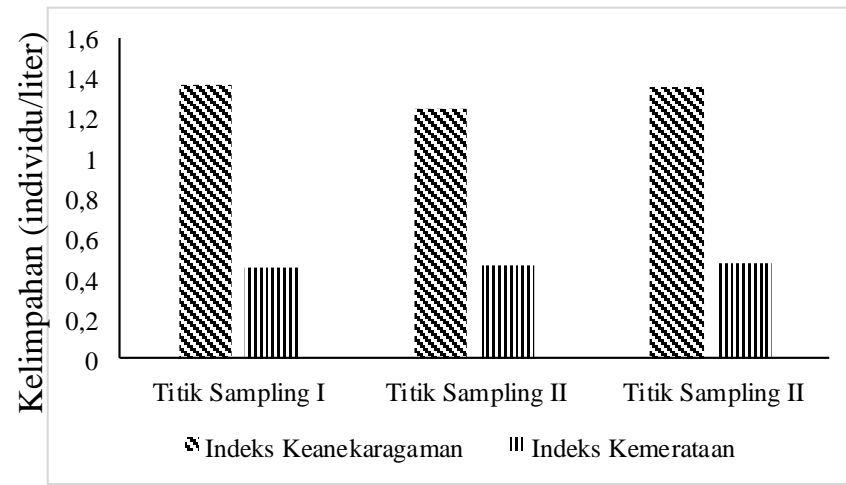

Gambar 2. Grafik Indeks Keanekaragaman dan Kemerataan Perairan Pantai Jeranjang

Kelimpahan spesies diatom di Pantai Jeranjangadalah 786,94 individu/liter. Skeletonema costatum merupakan spesies dengan nilai kelimpahan tertinggi yaitu 471,66individu/liter, sedangkan Biddulphia obtusa, Coscinodiscus radiatus, Cymbella obtusicula, Pleurosigma intermedium, dan Trichodesmium merupakan spesies dengan nilai kelimpahan terendah yaitu 0,27individu/liter. Spesies yang mengalami kelimpahan tertinggi ini diduga terkait dengan kondisi perairan karena rendahnya curah hujan sehingga kandungan bahan organik menjadi tinggi. Menurut Arinardi et al. (1997),costatum dapat memanfaatkan kadar zat hara lebih cepat daripadadiatom lainnya.Selain itu, Skeletonema costatum memiliki kisaran geografis luas baik di perairan iklim yang sedang maupun tropis. Rudiyanti (2011) berpendapat bahwa sebagian besar diatom sangat peka terhadap perubahan kadar garam dalam air.

Terdapat perbedaan mencolok nilai penting spesies anggota kelasBacillarophyceaedari tiga titk sampel penelitian. Spesies yang memiliki nilai penting terbesar adalah Skeletonema costatumyaitu 68,54\%, sedangkan Biddulphia obtusa, Coscinodiscus radiatus, Cymbella obtusiucula, Pleurosigma intermedium, dan Trichodesmium contortummemiliki nilai penting terkecil yaitu $0,75 \%$.

Kondisi perairan di Pantai Jeranjang masih dalam kategori normal. Dilihat dari kondisi lingkungan yang masih dalam batas normal dan tidak menyebabkan Blooming pada jenis-jenis spesies yang berbahaya. Sehingga dapat dikatakan bahwa, keberadaan PLTU di sekitaran perairan Pantai Jeranjang tidak berpengaruh terhadap kualitas perairan Pantai Jeranjang.Menurut Anderson et al.(2012) kecenderungan kelimpahan diatom ini akan menjadi acuan dalam memprediksi kejadian blooming. Hal tersebut dapat dilakukan dalam jangka panjang agar terlihat kecenderungan di mana puncak dari kelimpahan diatom tersebut khususnya spesies berbahaya.
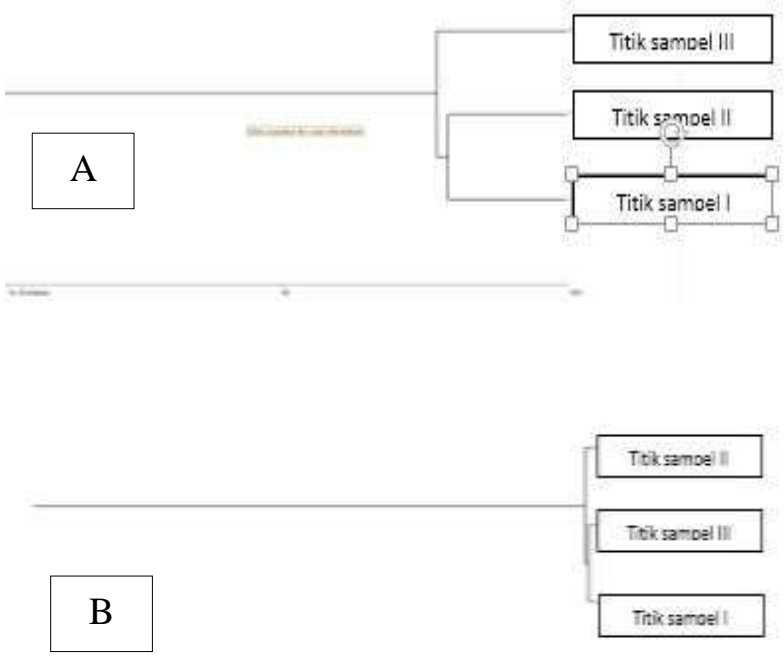


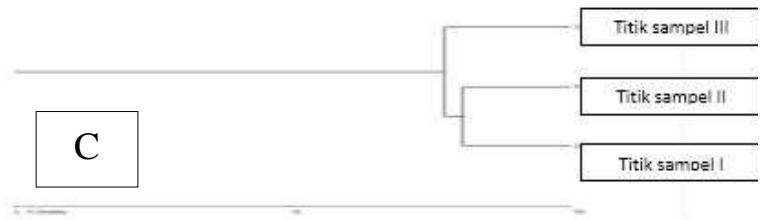

Gambar 3.Dendogram Hasil "The Bray Curtis Cluster Analyzis": (A. Data Parameter Biologi, B. Data Parameter Lingkungan. C. Data Parameter Gabungan)

$\begin{array}{ccr}\text { Gambar } & 3 & \text { memperlihatkan } \\ \text { persentase } & \text { kemiripan } & \text { tertinggi }\end{array}$
berdasarkan parameter biologi terdapat antara titik sampel I dan titik sampel II sebesar 78,78\%, dan titik sampel III terhubung dengan kelompok titik sampel I-II dengan persen ke sebesar 77,23\% (Gambar 4.9). Berbeda dengan persentase berdasarkan parameter biologi, persentase kemiripan tertinggi berdasarkan parameter lingkungan terdapat antara titik sampel I dan titik sampel III sebesar 99,03\%, dan titik sampel II terhubung dengan kelompok titik sampel I-III dengan persen kemiripan 98,41\%. Sedangkan persentase kemiripan tertinggi berdasarkan gabungan antara parameter biologi dan parameter lingkungan terdapat diantara titik sampel I dan titik sampel II yaitu sebesar $80,63 \%$, dan titik sampel III terhubung dengan kelompok titik sampel I-II dengan persen kemiripan 77,23\%.

Pada penelitian ini ditemukan spesies-spesies berbahaya dari genus Chaetoceros yaitu Chaetoceros affine, $C$. brave, $C$. didymus, $C$. laeve dan $C$. subsecendum. Spesies-spesies tersebut mengakibatkan masalah pada sistem pernapasan dan sistem pencernaan yang sifatnya tidak beracun, namun dari segi struktur yang berduri-duri dan tajam sehingga dapat menyebabkan kerusakan pada sistem pencernaan serta pernapasan pada avertebrata dan ikan jika spesies tersebut mengalami Blooming (terjadi ledakan populasi) (Hallegraeff, 1993).

\section{KESIMPULAN}

Kesimpulan yang bisa ditarik dari hasil penelitian ini, adalah:

1. Di Pantai Jeranjang teridentifikasidiatom yang terdiri dari 1 Kelas, 2 ordo, 17 genus, serta 26 spesies, dan kelimpahan diatom yaitu 9447 individu/liter.

2. Indeks keanekaragaman dan indeks kemerataanspesies berturut-turut adalah 1,38 dan 0,42.

3. Faktor fisik kimia (salinitas, suhu air, dan suhu udara) perairan Pantai Jeranjang yang diukur dalam penelitian ini masih berada pada kisaran yangmendukung pertumbuhan dan perkembangan diatom.

\section{DAFTAR PUSTAKA}

Al Idrus, A. 2014. Mangrove Gili Sulat Lombok Timur. Mataram: Arga Puji Press.

Al-Kandari, M., F. Y. Al-Yamani, dan K. Al-Rifaie. 2009. Marine Phytoplankton Atlas of Kuwait's Waters. Kuwait : Kuwait Institute for Scientific Research.

Anderson, D. M.,B. Reguera, G. C. Pitcher dan H. O.Enevoldsen. 2010. The IOC International Harmful Bloom Program: History and Science Impacts. Oceanography, 23 (3): 73-85. 
Arinardi, O.H, A.N. Sutomo, S. A. Yusuf, Trimaningsih, E. Asnaryanti dan S. H Riyono. 1997. Kisaran Kelimpahan dan Komposisi Plankton Predominan di Perairan Kawasan Timur Indonesia. Pusat Penelitian dan Pengembangan Oseanografi Lembaga Ilmu Pengetahuan Indonesia, 4(2): 130137.

Bellinger, E. G. dan D. C. Sigee. 2015. Freshwater Algae Identification and Use as Bioindicators. Second Edition. USA: John Wiley \& Sons, Ltd.

Choirun, A., S. H. J. Sari dan F. Iranawati. 2015. Identifikasi Fitoplankton Spesies Harmfull Algae Bloom (HAB) Saat Kondisi Pasang di Perairan Pesisir Brondong, Lamongan, Jawa Timur. Jurnal Ilmu Kelautan dan Perikanan, 25 (2): 58-66.

Davis, C. C. 1955. The Marine and Freshwater Plankton. USA: Michigan State University Press.

Fitriana, Y. R. 2006. Keanekaragaman dan Kemelimpahan Makrozoobentos di Hutan Mangrove Hasil Rehabilitasi Taman Hutan Raya Ngurah Rai Bali. Jurnal Biodiversitas, 7 (1): 67-72.

Haninuna, E.D., N. Gimin., R. Kaho dan M. R. Ludji. 2015. Pemanfaatan Fitoplankton sebagai Bioindikator Berbagai Jenis Polutan di Perairan Intertidal Kota Kupang. Jurnal Ilmu Lingkungan, 13(2):72-85.

Hallegraeff, G. M.. 1993. A Review of Harmful Algal Blooms and Their
Apparent Global Increase.

Phycologia,32 (2): 79-99.

Japa, L. 2000.Seasonal Succession of Phytoplankton Communities in Lombok Indonesian Coastal Waters, with Emphasis on Species of the Diatom Genera Pseudonitzshia and Thalassiosira.Thesis. Universitas Tasmania.

Kim, Chong-cun. 2010. Algal Flora of Korea: Freshwater Diatims $I$. Korea: Junghaengsa, Inc.

Nontji, A. 2008. Plankton laut. Jakarta : LIPI Press.

Odum. E. P. 1993. Dasar-dasar Ekologi. Edisi Ketiga. Tjahjono Samingan dan B. Srigando (penerjemah). Yogyakarta: Gadjah Mada University Press.

Park, J. G. 2012. Algal Flora of Korea. Volume 5 Number 1. Cyanophyta: Cyanophyceae: Chroococcales, Oscillatoriales Freshwater Cyanoprokaryota I. Korea :Junghaengsa, Inc.

Purnomo, A., A. I.K. Junitha dan N.M. Suartini. 2015. Variasi Spesies Diatom pada Tipe Perairan Berbeda untuk Kepentingan Forensik sebagai Petunjuk Kematian Akibat Tenggelam. Jurnal Simbiosis, 3(1):247-257.

Romimohtarto, K. dan S. Juwana. 2001. Biologi Laut Ilmu Pengetahuan tentang Biota Laut. Jakarta: Djambatan.

Rudiyanti, S. 2011. Pertumbuhan Skeletonema costatum pada 
Berbagai Tingkat Salinitas Media. Skripsi. Universitas Diponegoro.

Siregar, S.H, A. Mulyadi. Dan O.J.Hasibuan. 2008. Struktur Diatom Epilitik (Bacillariophyceae) pada Lambung Kapal di Perairan Dumai Provinsi Riau. Journal of environmental Science, 2(2): 19785283.

Smith, G, 1950. The Fresh Water Algae of The United States. Toronto: McGraw-Hill Book Company, Inc.

Soeprobowati, T. R. dan S.W.A. Suedy. 2010. Komunitas Diatom pada Ekosistem Mangrove Pantai Utara Jawa Tengah. Jurnal Sains dan Matematika, 18(3):94-102.

Soeprobowati, T. R. 2011. Variabilitas Keanekaragaman dan Distribusi Vertikal Diatom Danau Rawa Pening.Jurnal Sains dan Matematika, 19(3):65-70.

Susiati, H.S. dan Yarianto, S. B. 1999. Perkiraan Dampak PLTN Terutama Limbah Termal Terhadap Ekosistem Laut. Jurnal Pengembangan Energi Nuklir, 1(1):25-35.

Thomas,C.R. 1997. Marine Plankton Identification. London: Academic Press.

Wehr, J. D. dan R. G. Sheath. 2003. Freshwater Algae of North America Ecology and Classification.. USA: Academic Press an imprint of Elsevier Science. 